\title{
System Estimation of GVAR with Two Dominants and Network Theory: Evidence for BRICs ${ }^{1}$
}

\author{
Konstantinos N. Konstantakis and Panayotis G. Michaelides* \\ National Technical University of Athens
}

Efthymios G. Tsionas

Lancaster University

Chrysanthi Minou

Panteion University

\begin{abstract}
The dynamics of the traditional economic structures changed dramatically in the US and globally after 2006. In this context, the need for modeling complex macroeconomic interactions, has led us to develop an upgraded compact global (macro)econometric GVAR model, which is capable of incorporating both the complex interdependencies that exist between the various economic entities and the fact that in the global economy more than one of these entities could have a predominant role, without neglecting the channels of trade and finance. Additionally, based on the trade weight matrix that lies in the core of the GVAR framework, we provide both an analytical procedure and an ex-post econometric criterion for the selection of dominant entities. We demonstrate the dynamics of our model by focusing on the impact of a potential slowdown in the BRICs on the US and EU17 economies. According to our findings, the dominant economies are those of the USA and EU17, while the results suggest that EU17 is more vulnerable than the USA to shocks from the BRICs, implying that a potential slowdown in the BRICs will primarily affect the EU17 economy. Clearly, the proposed model can be easily used for analyzing a number of transmission mechanisms, contagion effects and network interdependencies in various settings.
\end{abstract}

Keywords: GVAR, Dominant, System estimation, BRICs, Crisis, Trade, Finance

JEL Classification: C32, G21

\footnotetext{
${ }^{1}$ We are indebted to the Editor, Sushanta Mallick, and the two anonymous referees for their constructive comments that have helped us improve the paper significantly. The usual disclaimer applies.

* Contact Author: Laboratory of Theoretical \& Applied Economics, School of Applied Mathematics \& Physics, National Technical University of Athens, Greece, Heroon Polytechneiou 9, 157.80, Zografou Campus, Tel: 302107721624; fax: +302107721618, email: pmichael@central.ntua.gr.
} 


\section{INTRODUCTION}

Over the last years, we are in the middle of a devastating global crisis that has significantly affected the economic conditions of the two major economic regions of the world, USA and EU17. According to the World Economic Outlook (2013), the IMF cut its global GDP forecast to $3.1 \%$ from $3.3 \%$, since growth in advanced economies was trimmed from $1.3 \%$ to $1.2 \%$, due to both the EU17 and the US weakness, while emerging markets growth was cut by $0.3 \%$ to $5 \%$. In this context, the so-called BRICS account for about $20 \%$ of world GDP and 55\% of the output of emerging and developing economies (World Economic Outlook, 2013). Nevertheless, the impact of a potential slowdown of BRICs on other major economies (e.g. US, EU) has attracted limited attention in the literature, so far.

In this paper we attempt to shed light on the impact of $\mathrm{BRICs}^{2}$ on the two major economic regions of EU17 and US. Of course, when attempting to model the complex interdependencies between the emerging economies of BRICs and the major economies of US and EU one should not neglect neither the predominant role of US and EU in the global economy, nor the fundamental channels of trade and finance that are hailed to be the most important channels of transmission (e.g. Cetorelli and Goldberg 2011).

In this context, the GVAR approach introduced by Pesaran et al. (2004) would be a relevant tool for the analysis of such complex dynamics. In the GVAR framework, it is widely accepted that the US could be considered as being a dominant economy in the model Chudik, and Pesaran (2013). Nevertheless, the use of US economy as the only dominant unit in the GVAR model is an ad-hoc approach that is, thus far, justified solely based on economic

\footnotetext{
${ }^{2}$ For a thorough discussion on the BRIC economies and their complex dynamic interdependencies see inter alia Cakir and Kabundi (2013), Allegret and Sallenave (2014), and Dreger and Zhang (2014).
} 
intuition, as opposed to formal econometric methods. To this end, there are two predominant research questions on the topic of dominant units in a GVAR framework: (a) is the USA indeed dominant according to formal methods? (b) Is there any other dominant economy in the model, and to what extent the introduction of a second dominant unit in a GVAR framework will affect the implied results of the model?

To this end, in this paper we construct an upgraded compact (macro)econometricmodel that incorporates both the complex interdependencies that exist between the various economic entities and the fact that in the global economy more than one of these entities could have a predominant role. In this context, we modify the GVAR model featuring one dominant economy introduced by Chudik and Pesaran (2013) so as to be able to accommodate more than one dominant entities. Additionally, based on the trade weight matrix that lies in the core of the GVAR framework, we provide both an analytical procedure and an ex-post econometric criterion for the selection of the dominant entities.

The present paper contributes to the literature as follows: (a) it proposes system estimation for the GVAR with $K$ dominants; (b) it formally estimates a GVAR with two (2) dominant economies; (c) it sets out a formal method for indentifying the number of dominant entities in a GVAR framework; (d) it sets out a novel method based on network theory for selecting the dominant entities; (e) it compares the estimation results of GVAR using one dominant and two dominant economies, respectively; (e) it estimates how a slowdown in the BRICS will affect EU17 \&USA.

The remainder of the paper is structured as follows: Section 2 sets out the proposed methodology; Section 3 presents the empirical results; Section 4 provides a brief discussion of the main results; Section 5 concludes. 


\section{METHODOLOGY}

The Global VAR approach (GVAR) provides a flexible technique for assessing relationships between economic variables and constitutes a useful tool for analyzing the transmission of economic shocks between economic regions. While factor augmented vector autoregressions (FAVAR) could be viewed as an alternative approach to GVAR (see e.g. Bernanke et al. 2005; Laganá and Mountford 2005), the number of estimated factors used in FAVAR would be different for the different countries and it is not clear how they relate to each other globally, according to Dees et al. (2007a). ${ }^{3}$

The present work builds on the work introduced by Pesaran et al. (2004) and developed through several contributions. For instance, Pesaran and Smith (2006) showed that the VARX* models could be derived as solutions to a DSGE model. Dées et al. (2007b) presented tests for controlling for the long-run restrictions. Furthermore, Chudik and Pesaran (2011) derived the conditions under which the GVAR approach is applicable in a large system of endogenously determined variables. Also, the GVAR model was applied to a variety of research questions, such as the international linkages of the euro area (Dées et al. 2005, 2007a), a credit risk analysis (Pesaran et al. 2006), the construction of measures of steady-state of the global economy (Dées et al. 2009), an analysis of the UK's and Sweden's decision not to join EMU (Pesaran et al. 2007), the application of the GVAR approach to the issue of international trade and global imbalances in Greenwood-Nimmo et al. (2010), Bussière et al. (2012), Konstantakis and Michaelides (2014).

\footnotetext{
${ }^{3}$ In this spirit, see Kapetanios and Pesaran (2007) who argue that GVAR estimators perform better than the corresponding ones based on principal components. Also, Korobilis (2013a) proposed a FAVAR model with time-varying coefficients and stochastic volatility whose coefficients and error covariances change gradually over time or are subject to abrupt breaks. His model showed that both endogenous and exogenous shocks to the US economy resulted in high inflation volatility during the 1970 s and ' 80 s.
} 
Furthermore, until recently, each country was treated in a "small economy" framework (Schmitt-Grohe and Uribe, 2003). There the idea was that all foreign economies are typically approximated by one representative economy constructed as a weighted average of foreign economies, while the rest of the countries' aggregate variables are generally treated as exogenous to the home economy. However, Chudik and Straub (2011) demonstrated recently that such an approach is justified only if no country is dominant. In a similar vein, recently Chudik and Smith (2013), following Chudik and Pesaran (2013), derived a GVAR approach as an approximation to an Infinite-Dimensional VAR (IVAR) model corresponding to the world featuring one dominant economy, i.e. the USA.

\subsection{The System GVAR Model}

Consider a GVAR with $i=1, \ldots, N$ small open economies and $k=1, \ldots, K$ large economies. The VARX model of each small open economy:

$y_{i, t}^{\prime}=a_{i 0}+\Phi\left(L_{1}\right) y_{j, t}^{\prime}+\Phi\left(L_{2}\right) y_{i, t}^{\prime *}+\Phi\left(L_{3}\right) g_{i, t}^{\prime}+u_{i, t}, j \epsilon\{1, \ldots, N, N+1, \ldots N+k\}$ (1)

where $a_{i 0}$ denotes a $(1 x m)$ vector of $m$ intercepts, $y_{i, t}^{\prime}=\left[y_{i_{1}, t}, \ldots, y_{i_{m}, t}\right]$ denotes the transpose of a $(1 \times m)$ vector $y_{i, t}$ of $m$ variables for each economy $i=1, \ldots, N$ $\begin{array}{llll}\text { expressing the country } & \text { specific }\end{array}$ $y_{j, t}^{\prime}=\left[y_{i_{1}, t}, \ldots, y_{i_{m}, t}, y_{i_{k_{1}}, t}, \ldots, y_{i_{k_{m}}, t}, \ldots, y_{i_{k_{K}} . t}, \ldots, y_{i_{k_{K}} . t}\right]$ denotes the transpose of a $((m+K m) x 1)$ endogenous variables. The $m$ endogenous variables are augmented by the $\mathrm{km}$ variables of the dominant entities, and $\Phi\left(L_{1}\right)$ is the $\left((m+K m) x L_{1}\right)$ matrix of the associated lag polynomial; $y_{i, t}^{\prime}{ }^{*}=\left[y_{i_{1}, t}{ }^{*}, \ldots, y_{i_{m}, t}{ }^{*}\right]$ denotes the transpose of a $(m x 1)$ vector $y^{*}{ }_{i, t}$, of $m$ foreign-specific variables for each economy $i=1, \ldots, N-1$ and $\Phi\left(L_{2}\right)$ is 
an $\left(m x L_{2}\right)$ matrix of the associated lag polynomial; $g_{i, t}^{\prime}=\left[g_{i_{1}}, \ldots, g_{i_{p}}\right]$ denotes the transpose of a $(p x 1)$ vector of $p$ global variables for each economy $i=1, \ldots, N$ while $\Phi\left(L_{3}\right)$ is an $\left(p x L_{3}\right)$ matrixof the associated lag polynomial. In general, $m$ and $p$ may be allowed to vary between economies.

Traditionally, each country VAR is estimated and then the endogenous variables are stacked together and solved. However, this is not always expected to approximate reality very satisfactorily since the models interact simultaneously through the dominant variables incorporated in all models as well as through the possible existence of global variables. Hence, it is reasonable to assume: $\operatorname{Cov}\left(u_{i, t}, u_{c, t}\right) \neq 0 \forall \mathrm{i} \neq \mathrm{c}, \mathrm{i}, \mathrm{c}=1, \ldots, \mathrm{N}$ since the variables of the dominant entities and of the global variables clearly act as common regressors. By grouping together the $y_{i, t}$ for the $i=1, \ldots, N$ small open economies, except for the variables that correspond to the dominant entities, we get:

$$
B_{i} y_{i, t}=\Gamma z_{\xi, t}+u_{i}(2)
$$

where: $B_{i}=\left(I ;-\Phi\left(L_{1}\right)\right)$, is a $\left(1 x m L_{1}\right)$ vector of coefficients of the country's $i=1, \ldots, N$ specific variables; $z_{\xi, t}=\left[y_{i_{1}, t}{ }^{*}, \ldots, y_{i_{m}, t}{ }^{*} ; y_{i_{k_{1}}, t}, \ldots, y_{i_{k_{m}}, t}, y_{i_{K_{1}}, t}, \ldots, y_{i_{K_{m}} . t} ; g_{i_{1}}, \ldots, g_{i_{p}}\right]$ is the transpose of a $(1 x M)$ vector of variables, $M=L_{2} m k+L_{3} p+2$; while $\Gamma_{i}$ is a $(M x m)$ matrix of coefficients and $u_{i}^{\prime}=\left[u_{1, t}, \ldots, u_{N, t}\right]$ is a $(1 x N)$ vector of idiosyncratic shocks such that $u_{i} \sim N\left(0, \Sigma_{i i}\right)$ where the covariance of the error term is:

$$
\left(\begin{array}{c}
u_{1, t^{\prime}} \\
\vdots \\
u_{N, t^{\prime}}
\end{array}\right) \sim N\left(0, \Omega=\left(\begin{array}{ccc}
\Sigma_{11} \Sigma_{12} & \ldots & \Sigma_{1 N} \\
\Sigma_{21} \Sigma_{22} & \ldots & \Sigma_{2 N} \\
& \ldots & \\
\Sigma_{N 1} \Sigma_{N 2} & \ldots & \Sigma_{N N}
\end{array}\right)\right)
$$

and each $\Sigma_{i l}$, represents a covariance matrix between the error terms of countries $i$ and $l$, $i, l=1, \ldots, N$.

For the foreign-specific variables: 
$y_{i, t}{ }^{* \prime}=\sum_{c=1}^{N} w_{i, c} y_{c, t}{ }^{\prime}=w_{i} Y_{t}(\mathbf{3})$

$w_{i}$ represents the vector of trade weights of country $i$ with countries $c \neq i, i=1, \ldots, N-$ $1, w_{i i}=0$. If $B_{i}$ is non-singular,the GVAR model of the small open economies is:

$y_{i, t}=\Delta_{i} z_{\xi, t}+v_{i}^{\prime}, i=1, \ldots, N(4)$

where: $\Delta_{i}=\Gamma_{i} B_{i}^{-1}$ and $v_{i}=B_{i}^{-1} u_{i}^{\prime}$.

According to Pesaran et al. (2004) the GVAR model represented by the system of equations in (4) is estimated using equation-by-equation Ordinary Least Squares (O.L.S.). Nevertheless, since in equation (4) the variables $Z_{\xi, t}$ are not the same across the $i=1, \ldots, N$ economic entities, it is obvious that $\operatorname{Cov}\left(v_{i}, v_{j}\right) \neq 0, i, j \in\{1, \ldots, N\}$, and thus the GVAR estimators obtained via O.L.S. would not belong to the class of best linear unbiased estimators (BLUE). To this end, for the estimation of the system of equations in (4), we could have used seemingly unrelated regressions equations (SURE).

However, since we are interested in incorporating the dominant units in the system of equations represented in (4), we proceed using standard notation and following the same procedure. Hence, the GVAR for the $k=1, \ldots, K$ dominant economies is:

$$
y_{k, t}=\Delta_{\kappa} z_{\zeta, t}+v_{\kappa}{ }^{\prime}, k=1, \ldots, K(5)
$$

where: $\Delta_{k}=B_{k}^{-1} \Gamma_{k}$ and $v_{k}{ }^{\prime}=B_{k}^{-1} u_{k}^{\prime}$.

According to Pesaran et al. (2004) and Chudik and Pesaran (2013), the system of equations in (5) should be estimated separately from the GVAR system presented in (4). Nevertheless, since the two systems share common regressors, it is possible to stack the two GVAR models together and solve them simultaneously. To this end, the system of (4) and (5) is: 


$$
\begin{gathered}
\left\{\begin{array}{c}
y_{i, t}=\Delta_{i} z_{\xi, t}+v_{i}{ }^{\prime}, i=1, \ldots, N \\
y_{k, t}=\Delta_{\kappa} z_{\zeta, t}+v_{\kappa}{ }^{\prime}, k=1, \ldots, K
\end{array}\right\} \Rightarrow \\
\left\{\begin{array}{c}
y_{i, t}^{\prime}=\widetilde{\widetilde{\Gamma}_{\imath} z_{J, t}}+\Lambda_{i} z_{i, t}{ }^{*}+\omega_{i, t}^{\prime}, i=1, \ldots, N \\
y_{k, t}^{\prime}=\widetilde{\Gamma}_{k} \widetilde{z_{k, t}}+\Lambda_{k} z_{k, t}{ }^{*}+\omega_{k, t}^{\prime}, k=1, \ldots, K
\end{array}\right\}(6)
\end{gathered}
$$

where: $\widetilde{z_{\jmath, t}}=\left[y_{i, t-1}, \ldots, y_{i, t-L_{1}} ; y_{k, t-1}, \ldots, y_{k, t-L_{2}} ; y_{p, t-1}, \ldots, y_{p, t-L_{3}}\right]$ represents the own lags of the country-specific variables, the dominant entities and the global variables and $\widetilde{\Gamma}_{l}$ the respective coefficients; $z_{i, t}{ }^{* \prime}=\left[y_{i, t-1}{ }^{* \prime}, \ldots, y_{i, t-L_{2}}{ }^{* \prime}\right]$ are the foreign specific variables and $\Lambda_{i}$ the respective coefficients; $\widetilde{z_{k, t}}=\left[y_{k, t-1}, \ldots, y_{k, t-L_{4}} ; y_{p, t-1}, \ldots, y_{p, t-L_{6}}\right]$ represents the own lags of the dominant entities and the global variables and $\widetilde{\Gamma}_{l}$ the respective coefficients; $z_{k, t}{ }^{* \prime}=\left[y_{k, t-1}{ }^{* \prime}, \ldots, y_{k, t-L_{5}}{ }^{* \prime}\right]$ are the foreign specific variables and $\Lambda_{k}$ the respective coefficients. Finally, $\omega_{i, t}^{\prime}$ and $\omega_{k, t}{ }^{\prime}$ represent the error terms where $\omega_{k} \sim N\left(0, \Sigma_{k k}\right)$ and $\omega_{i} \sim N\left(0, \Sigma_{i i}\right)$ with:

$\operatorname{Cov}\left(\omega_{c}, \omega_{d}\right) \cdot \operatorname{Cov}\left(\omega_{f}, \omega_{g}\right) \cdot \operatorname{Cov}\left(\omega_{q}, \omega_{r}\right) \neq 0, \mathrm{c}, d=1, \ldots, N, f, g=1, \ldots, K, q, r=$ $1, \ldots, N+K(7)$

: since the $\widetilde{z_{\jmath}, t}$ has common regressors, the $\widetilde{z_{k, t}}$ has common regressors and $\widetilde{z_{\jmath}, t}$ and $\widetilde{z_{k, t}}$ have common regressors.

In this context, equations (6) are estimated using 3SLS (Zellner and Theil, 1962) and we call this System GVAR (SGVAR). We assess the results of the proposed SGVAR estimation using the so-called Generalized Impulse Response Functions (GIRFs). The GIRF are expressed as follows (Koop et al. 1996, Pesaran and Shin 1998):

$$
I_{j(n)}=\sigma_{j j}{ }^{-1 / 2}+B_{n} \sum e_{j} \forall n=1,2, \ldots(8)
$$


where: $I_{j(n)}$ is the Impulse Response Function $n$ periods after a positive standard error unit shock; $\sigma_{j j}$ is the $j$ th row and $j$ th column element of the variance-covariance matrix of the lower Cholesky decomposition matrix of the error term which is assumed to be normally distributed; $\mathrm{B}$ is the coefficients' matrix when inversely expressing the VAR model as an equivalent MA process and $e_{j}$ is the column vector of a unity matrix.

Finally, in order to assess the time profiles of the effects of the variables-specific shocks on the potential cointegrating relations in the SGVAR model presented earlier, we will make use of the respective Persistent Profiles (PP). In this context, the PP of the $j$-th cointegrating relation, namely $b_{j i}^{\prime} z_{i t}$, in the $\mathrm{i}$-th country $\left(j=1, \ldots r_{i}\right)$ at an horizon $n \in \mathbb{N}$ with respect to a variable specific shock to the l-th element of $y_{t}$ is given by the following expression:

$P P\left(b_{j i}^{\prime} z_{i t} ; \varepsilon_{l t}, n\right)=\frac{b_{j i}^{\prime} W_{i} B_{n} \Sigma_{\varepsilon} e_{l}}{\sqrt{\sigma_{l l}}}, n=1, \ldots N$ (9)

where: $\sigma_{l l}$ is the 1-th diagonal element of $\Sigma_{\varepsilon} ; e_{l}$ is a selection vector with its elements corresponding to the l-th variable in $y_{t}$ is unity and zero elsewhere and $B_{n}$ is the coefficients' matrix, when inversely expressing the VAR model as an equivalent MA process for the $\mathrm{n}$-th period.

\subsection{Calculating the Number of Dominant Economies}

In order to select the number of dominant entities in the dataset we investigate the eigenvalue distribution of a matrix $(Q)$ that accounts for the exchangeable quantities between the economies: 


$$
Q \equiv\left(\begin{array}{ccc}
q_{11} & \ldots & q_{1(N+K)} \\
\vdots & \ddots & \vdots \\
q_{(N+K) 1} & \ldots & q_{(N+k)(N+K)}
\end{array}\right) \equiv W x_{t}=\left(\begin{array}{cccc}
0 & w_{1,2} & \ldots & w_{1, N+K} \\
w_{2,1} & 0 & \ldots & w_{2, N+K} \\
\vdots & \ddots & \ldots & \vdots \\
w_{N+k, 1} & \ldots & & 0
\end{array}\right)\left(\begin{array}{c}
x_{1, t} \\
x_{2, t} \\
\vdots \\
x_{N+K, t}
\end{array}\right)
$$

where: $x_{t}$ is a $(\mathrm{N}+\mathrm{K}) \mathrm{x} 1$ vector of outputs and $W$ is the $(\mathrm{N}+\mathrm{K}) \mathrm{x}(\mathrm{N}+\mathrm{K})$ trade weight matrix, and the $q_{i j}$ element of matrix Q expresses the quantity of output that flows from economy $i$

to economy $j$. The row elements express the quantities supplied by one economy to all others. Column elements express quantities obtained by an economy from all others. Hence: $q_{i i}=0$.

In a seemingly unrelated publication, Bródy (1997) showed that the behavior of systems describing economic interconnections depends on the ratio of the modulus of the subdominant eigenvalues to the dominant one, such that a ratio close to zero implies negligible power of this economy. Let $\lambda(\mathrm{pf})=\lambda(1)$ denote the dominant eigenvalue of $\mathcal{Q}$ and the normalized eigenvalues: $\rho(\mathrm{i}) \equiv|\lambda(i) / \lambda(p f)|, \quad \mathrm{i}=2, \ldots, \mathrm{N}+\mathrm{K}$ are the non-dominant normalized eigenvalues. The number of dominant economies is $i^{*}$, such that $\rho\left(i^{*}\right)>0.40$, since values $<0.40$ are practically negligible (Mariolis and Tsoulfidis, 2014). The fact that every normalized eigenvalue that is below the threshold of 0.40 could, without loss of generality, be considered negligible lies on the diminished impact of these eigenvalues in the overall stability of the system, which implies insignificant loss of information in its description.

\subsection{Network / Node Theory for selecting the Dominant Economies}

In a novel approach, we will make use of network theory to virtually select the dominant economies using the concept of centrality (Freeman 1979), which is widely used to identify the most important nodes of a graph. 
Any selected panel of world economies can be represented by a finite graph, $G(V, E)$, where $V$ accounts for the vertex set i.e. the set of nodes in the graph and $E$ accounts for the edge set, i.e. the number of edges in the graph. Therefore, without loss of generality, economies could be depicted as nodes, while the exchangeable quantities between the economies could be depicted by the edges of a graph. In this context, the vertex set would contain all the economies incorporated in the model i.e. $V=\{1,2, \ldots, N+K\}$, while the edge set would contain the row elements of matrix Q, so the edge set would be of the form $E=\left\{x_{11}, \ldots, x_{1 N+K} ; \ldots ; x_{N+K, 1}, \ldots, x_{N+K, N+K}\right\}$. To this end, the edge $x_{i j}, i, j \in\{1, \ldots, N+$ $K\}$ represents the product of economy i that flowsto economy $\mathrm{j}$.

In order to examine which nodes are dominant, we use the three main vertex theory measures, namely: (i) degree centrality, (ii) alter-based centrality, and (iii) beta centrality.

(i) The degree centrality of a node shows how connected a node is to the other nodes in the graph. See, among others, Ying et al. (2014) and Bates et al. (2014). In our case, we normalize the flows $x_{i j}, i, j \in\{1, \ldots, N+K\}$ with the total amount of flows to $i, i \in$ $\{1, \ldots, N+K\}$ economies incorporated in the model using the formula:

$$
z_{i j}=\frac{x_{i j}}{\sum_{i=1}^{N+K} \sum_{j=1}^{N+K} x_{i j}}
$$

so as to produce weights instead of flow quantities. Therefore, we create a new weighted graph, $G^{\prime}\left(V, E^{\prime}\right)$ where the vertex set remains unaffected i.e. $V=\{1,2, \ldots, N+K\}$ economies, while the edge set since every edge is transformed to $E^{\prime}=\left\{z_{11}, \ldots, z_{1 N+K} ; \ldots ; z_{N+K, 1}, \ldots, z_{N+K, N+K}\right.$. The centrality, $c_{i}$, of each node is given by the following formula: 


$$
c_{i}=d(i) \sum_{j=1}^{N+K} Z_{i j}(12)
$$

where $d(i)$ is the degree of each node i.e. the number of ties with the rest of the nodes (Fagiolo et al. 2008). In this context, the dominant economies are those, which exhibit the largest centrality. Hence, the largest $c_{i}$ corresponds to the dominant economy, the second largest $c_{i}$ to the second-dominant economy, and so on.

However, degree centrality does not take into consideration how the neighbors of each node interact with the rest of the nodes of the vertex. In this context, we take into account two additional measures of node centrality, namely alter-based power and beta power, that take into consideration both the nearby and the distant neighbors of a node (Bonacich and Lloyd, 2001).

(ii) Altered based power of a node $i$, identifies the most central nodes of a vertex by taking under consideration both the degree centrality of the neighboring nodes, and their respective weights. Alter-based centrality is given by the following formula:

$$
A C_{i}=\sum_{i=1}^{N+K}\left(z_{i j} * c(i)^{-1}\right)(13)
$$

where: $z_{i j}, i, j \in\{1, \ldots, N+K\}$ are the weights between each node, $i$, with the rest of the $j$ nodes and $c(i)^{-1}$ is the inverse degree centrality of each node in the network. In this sense, a node is central if it is connected to nearby non-central other nodes (Neil, 2011). The larger value of alter based power of a node corresponds to the first dominant economy, the second largest to the second dominant and so on.

(iii) Beta based power of a node, $i$, was developed by Bonacich (1987) as an extension of the eigenvector centrality (Bonacich 1972), and can identify the centrality power of a node 
according to either their distant neighbors or their nearby neighbors of the specific node. It is given by the following formula:

$$
B C_{i}=(I-\beta R)^{-1} R(14)
$$

where: $I$ is the indentity matrix, $\beta$ is a discount parameter and $R=\left[z_{i j}\right], i, j \in$ $\{1, \ldots, N+K\}$ is the adjacency matrix. Different values of the discount parameter $\beta$ provide us with different centrality powers for the node $i$. In particular, according to the value of $\beta$ we have the following cases: (a) if $\beta \gg 0$ or $\beta \ll 0$ then the power centrality of a node, $i$, is based on the distant neighbors of the specific node and approaches the eigenvector centrality; and (b) if $\beta>0$ or $\beta<0$ then the power centrality of a node, $i$, is based on the nearby neighbors of the specific node and it approaches the alter-based power of a node; Apparently, the dominant economies are those with the greater values of beta based centrality power.

\subsection{Information Criterion for selecting the Dominant Economies}

In this sub-section, we will make use of the so-called Schwartz-Bayes Information criterion (SBIC) or, simply, BIC introduced by Schwartz (1978) in order to econometrically confirm the selected dominant entities. Let $L_{T}(o)$ be the maximum likelihood of the SGVAR system, described by the following equations:

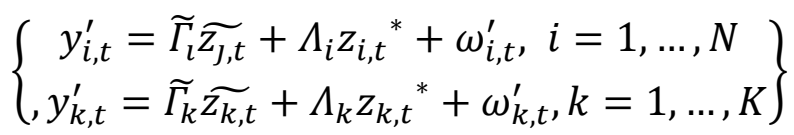


where: $t=1, \ldots, T$ is the time dimension which corresponds to the number of observations and $o=\max \{H, M\} \times m$ denotes the number of unkown parameters of the system of equations.

Following the methodology described in the previous section there exist $k^{*}$ dominant economies in the system. In order to test which of the $i=1, \ldots, N+K$ economies are dominant we need to calculate the BIC criterion for the different combinations of $k^{*}$ dominant economies regarding the system (15).

Let $\widehat{\Sigma_{k^{*}}}$, be the estimated variance of the above system of equations (15). Then the BIC criterion for each $k^{*}{ }_{i}, i=1, \ldots, N+K$ combination of dominant economies will be given by the following formula:

$$
c_{T}{ }^{3-S L S}\left(k^{*}{ }_{i}\right)=\ln \left(\operatorname{det}\left(\widehat{{k^{*}}_{l}}\right)+o \frac{\ln (T)}{T}(16)\right.
$$

The dominant combination of $\overline{k^{*}}{ }_{l}$ economies is the combination that optimizes the BIC, i.e. in mathematical terms: $\overline{k^{*}}=\operatorname{argmin}\left\{c_{T}{ }^{3-S L S}(i)\right\} .{ }^{4}$

Of course, the aforementioned selection strategy could easily be followed using some other relevant information criterion, e.g. AIC, etc. However, we have used BIC over other criteria, following Breiman and Freedman (1983) and Speed and Yu (1992), who have shown that BIC is an optimal selection criterion when used in finite samples.

\footnotetext{
${ }^{4}$ Please note that the same criterion could be used, ex-post, to assess the number of dominant economies that should be selected in a GVAR model, since the number of variables does not depend on the number of dominant economies but on the total number of economic entities that are included in the GVAR i.e. $i=$ $1, \ldots, K+N$.
} 
Finally, a number of fairly standard tests need to be carried out, such as stationarity, cointegration, optimum lag length, stability and asymptotic properties. See Appendix.

\section{EMPIRICAL RESULTS}

\subsection{Data and Variables}

The data are quarterly and cover the period 1992(Q1)-2014(Q4), fully capturing the ongoing recession. For all the economies that enter the SGVAR model i.e. USA, EU17, Brazil, Russia, India, China, Japan, Australia and Canada we used data ${ }^{5}$ regarding their exchange rates to the dollar, GDP deflator, GDP in current prices and interest rates ${ }^{6}$. The EU17 economy is considered as a single economy and includes the economies of: Austria, Belgium, Cyprus, Estonia, Finland, France, Germany, Greece, Ireland, Italy, Luxembourg, Malta, the Netherlands, Portugal, Slovak Republic, Slovenia and Spain.

All the data come from OECD's, main economic indicators database, while the data on the EU17 GDP come from the official Eurostat, National Accounts section. The implicit assumption is that the variables of global finance and global trade act as transmission channels of the crisis, see inter alia Xu, (2012), Cesa-Bianchi (2013), Eickmeier and Ng (2015).

Hence, regarding the global variables, we use the aggregate values of: (i) Worldwide Total Credit and (ii) Worldwide Total Trade, both in millions of dollars, which were obtained in constant 2005 prices from the World Data Bank. Additionally, in each VARX model we include (exogenous) dummy variables that account for the global financial crisis of

\footnotetext{
${ }^{5}$ When data were missing, following Pesaran et al. (2004) we intra/extra-polated the missing values.

${ }^{6}$ Note that in this work the interest rates used represent the discount rates of each economy. In other words, the interest rate used in determining the present value of a future payment for each economy, and come from the IMF site, International Financial Statistics section.
} 
2007-2009 as well as for the local/regional crises that some countries experienced during the period under investigation, like the Russian crisis of 1998, the lost decade of the Japanese economy, the currency crisis in Brazil etc.

Following Pesaran et al. (2004), in this work the weights are assumed to be constant over the whole sample and are equal to the average trade weights which are calculated using ECB's database, which is freely accessible. Also, using each economy's GDP deflator, $\mathrm{i}=1, . ., 9, G D P_{i}$ we calculated the GDP in constant 2005 prices using the formula:

$$
G D P_{2005_{i}}=\frac{G D P_{i} \text { current prices }}{G D P_{i} \text { deflator }}(17)
$$

Then, we made use of the exchange rate of each economy's, $i=1, . ., 9$, so as transform, $G D P_{2005_{i}}$, into dollars, using the formula:

$G D P_{i, 2005 \text { in } \$}=G D P_{2005_{i}} *$ exchange rate $_{i}(18)$

\subsection{Dominant Economies}

According to Brody's (1997) established methodology described earlier, the results undoubtedly indicate the existence of two dominant economies for which: $\rho\left(i^{*}\right)>0.4$ $\left(\rho_{1}=1, \rho_{2}=0.72\right)$.

Table 1: Centrality measures of economies

\begin{tabular}{|c|c|c|c|}
\hline Economy (i) & Degree Centrality, $\boldsymbol{c}(\boldsymbol{i})$ & Alter power, $\boldsymbol{A C}_{\boldsymbol{i}}$ & Beta power, $\boldsymbol{B C}_{\boldsymbol{i}}$ \\
\hline US & 1.321 & 1.724 & 0.445 \\
\hline EU17 & 1.831 & 1.757 & 2.498 \\
\hline
\end{tabular}




\begin{tabular}{|c|c|c|c|}
\hline JAP & 0.754 & 1.014 & 0.370 \\
\hline RUS & 0.806 & 0.595 & 0.172 \\
\hline CAN & 0.170 & 0.171 & 0.059 \\
\hline CHI & 0.139 & 0.093 & -0.021 \\
\hline BRA & 0.658 & 0.576 & -0.203 \\
\hline AUS & 0.894 & 0.906 & 0.097 \\
\hline IND & 1.184 & 0.607 & -1.530 \\
\hline
\end{tabular}

Next, we select the two dominant entities using the various centrality measures based on network theory, as described earlier. The: (i) degree of centrality, (ii) alter based power centrality and (ii) betabased power centrality of each node are presented in Table 1.

The results obtained by all the centrality measures employed for each economy, show that the economies of US and EU17 are the most central ones ${ }^{7}$ and, thus, may be considered as being dominant in the model. Notice that together the two economies account for more than $30 \%$ of global output and are usually considered as being two of the most powerful economies in the globe (CIA, 2013).

In order to confirm the selection of the dominant economies in our model and its relevant measures of centrality, we calculate the Bayes Information Criterion for the system as described earlier. In this context, we present the results in Table 2.

Table 2: Bayes Information criterion

\begin{tabular}{|c|c|}
\hline Dominant Pairs of Economies & BIC \\
\hline US and EU17 & -745.28 \\
\hline US and China & -635.64 \\
\hline
\end{tabular}

\footnotetext{
7 The increased centrality that the economies of Australia and India exhibit could be attributed to the fact that the sample of countries utilized in this paper covers sufficiently the main trading partners of these economies.
} 


\begin{tabular}{|c|c|}
\hline EU17 and China & -668.75 \\
\hline US and Japan & -521.28 \\
\hline EU and Japan & -333.59 \\
\hline Japan and China & -342.75 \\
\hline
\end{tabular}

According to the results in Table 2 the pair of dominant economies US - EU17 presents the lowest $\mathrm{BIC}$ value, compared to the rest of the pairs, which are the most likely alternative pairs for dominant economies in the model.

\subsection{Relevant Tests}

In what follows, we present the results of the various tests. To avoid any spurious effect, we continue our analysis by testing for the existence of unit roots in the various time series. In this paper we investigate the existence of unit roots in our time series data using the Phillips and Perron (1988) test. See Appendix. 


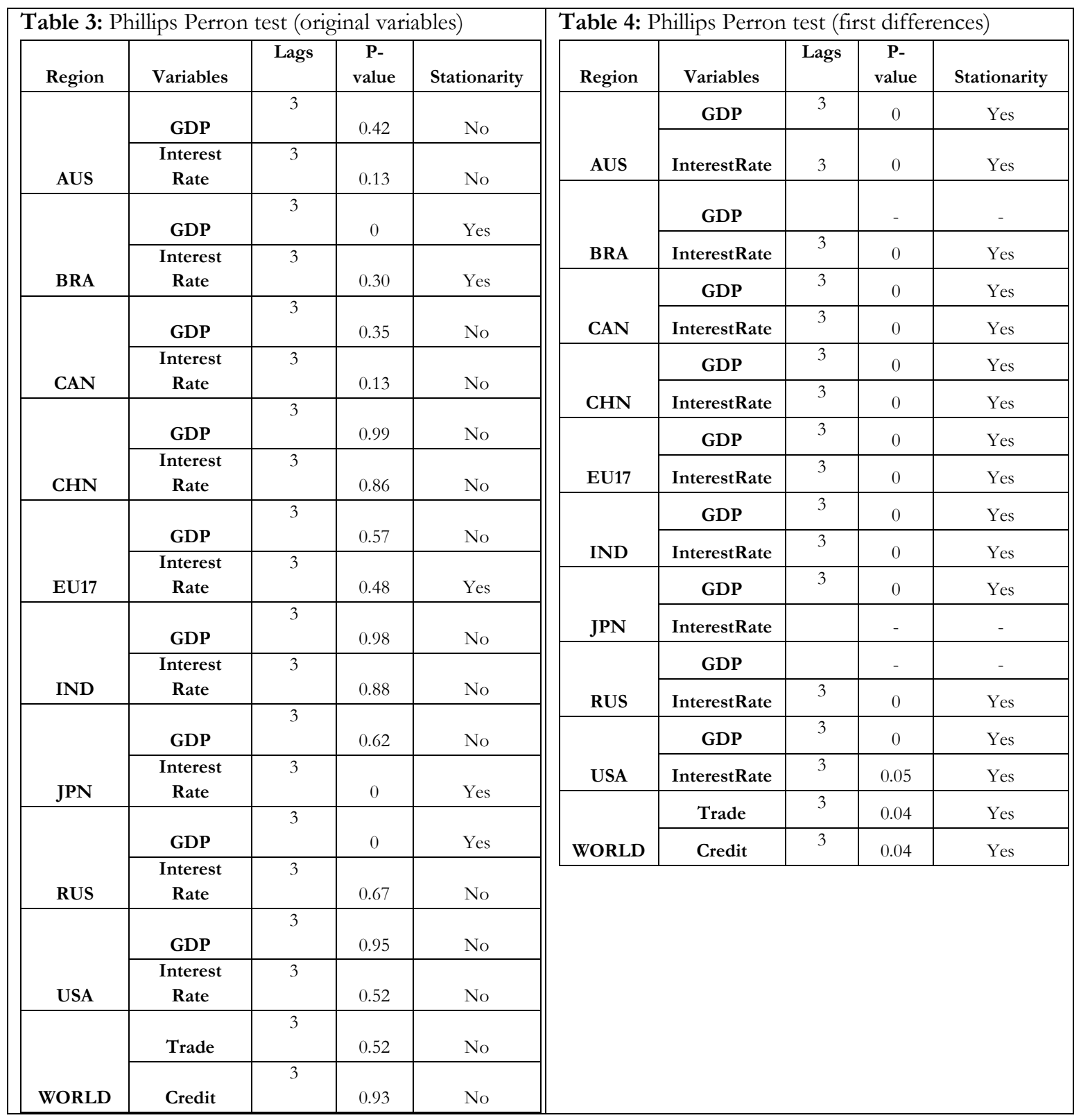

Most GDP variables were found to be stationary in their first differences (Table 4) except for the GDPs of Brazil and Russia that are stationary in levels (Table 3). The interest rates were also found to be stationary in first differences, except for that of Japan, which is stationary in levels. 
Next, in the presence of I(1) variables in the VARX's models of each economy, following standard econometric practice, we investigated the existence of possible long run relationships using the Johansen and Juselius (1990) methodology. See Appendix. The results in Table 5 suggest that cointegration is present in all the VARXs models..

Table 5: Johansen Cointegration test

\begin{tabular}{|c|c|c|c|c|c|c|}
\hline Economies & $\begin{array}{c}\text { Cointegration } \\
\text { Rank }\end{array}$ & Eigenvalue & $\begin{array}{c}\text { Log } \\
\text { Likelihood }\end{array}$ & $\begin{array}{c}\text { Trace } \\
\text { statistics }\end{array}$ & $\begin{array}{c}\mathbf{5 \%} \\
\text { Critical } \\
\text { value }\end{array}$ & Cointegration \\
\hline US & 1 & 0.51 & -243.91 & 21.34 & 29.68 & \\
\hline EU17 & 1 & 0.36 & -172.40 & 28.84 & 29.68 \\
\hline BRA & 3 & 0.18 & -56.20 & 14.53 & 15.41 \\
\hline RUS & 1 & 0.54 & -121.32 & 42.17 & 47.21 & \multirow{2}{*}{ Yes } \\
\hline IND & 1 & 0.57 & -164.21 & 54.22 & 68.52 & \\
\hline CHN & 1 & 0.58 & -180.52 & 66.54 & 68.52 \\
\hline JPN & 2 & 0.31 & -136.86 & 19.23 & 29.68 & \\
\hline CAN & 1 & 0.59 & -158.21 & 59.09 & 68.52 & \\
\hline AUS & 3 & 0.28 & -97.23 & 26.65 & 29.68 & \\
\hline
\end{tabular}

Next, having determined the number of cointegrating vectors that each VECX model has to incorporate, we proceed by selecting the optimum numbers of lags for each VECX model. The optimum lag length of each VECX is determined using the BIC (1978) criterion (Table 6). 
Table 6: Lag Length Selection Criterion

\begin{tabular}{|c|c|c|}
\hline Region & Optimal Lags & SBIC \\
\hline US & 2 & 11.24 \\
\hline EU17 & 2 & 10.52 \\
\hline BRA & 3 & 3.21 \\
\hline RUS & 3 & 5.22 \\
\hline IND & 2 & 4.32 \\
\hline CHN & 3 & 9.56 \\
\hline JPN & 5 & 4.35 \\
\hline CAN & 2 & 4.29 \\
\hline AUS & 3 & 3.78 \\
\hline
\end{tabular}

Having determined the VECX (p, q) specification for each economy in the GVAR model, we proceed by estimating the whole system of VECX models simultaneously using 3-SLS estimation. Following the notation presented earlier, the SGVAR estimation has the following basic components:

- $\quad i=1, . .7$

small

open

economies,

where:

$i=\{B R A, I N D, R U S, C H N, J P N, A U S, C A N\}$

- $\quad k=1,2$ dominant economies where $k=\{U S, E U 17\}$

- $y_{j, t}=\left(G D P_{j, t}\right.$, Interest Rate $\left._{j, t}\right\}$ where $j=1, \ldots N+K$

- $g_{j, t}=\left\{\right.$ Credit $_{t}$, Trade $_{t}$, Global Crisis $_{t}$, Regional Crisis $\left._{j, t}\right\}$

- where: $j=1, \ldots N+K$

Having estimated the GVAR system, we compute the persistent profiles of the country specific shocks, following, Pesaran and Shin (1998) and Pesaran et al. (2007). Each persistent profile shows the time profiles of the effects of the variables-specific shocks on the potential cointegrating relations in the SGVAR model. 


\subsection{Persistent Profiles}

Figure 1, presents the persistent profiles of the EU17 GDP to shocks in the GDP of the BRICs. The results clearly indicate that the EU17 GDP is only affected in the short-run, i.e. less than five (5) quarters, by the various shocks in the GDP of the BRICs economies since all the persistent profiles die out after approximately five (5) quarters.

Figure 1: Persistent Profiles of EU17 GDP to shocks in the BRIC's GDP

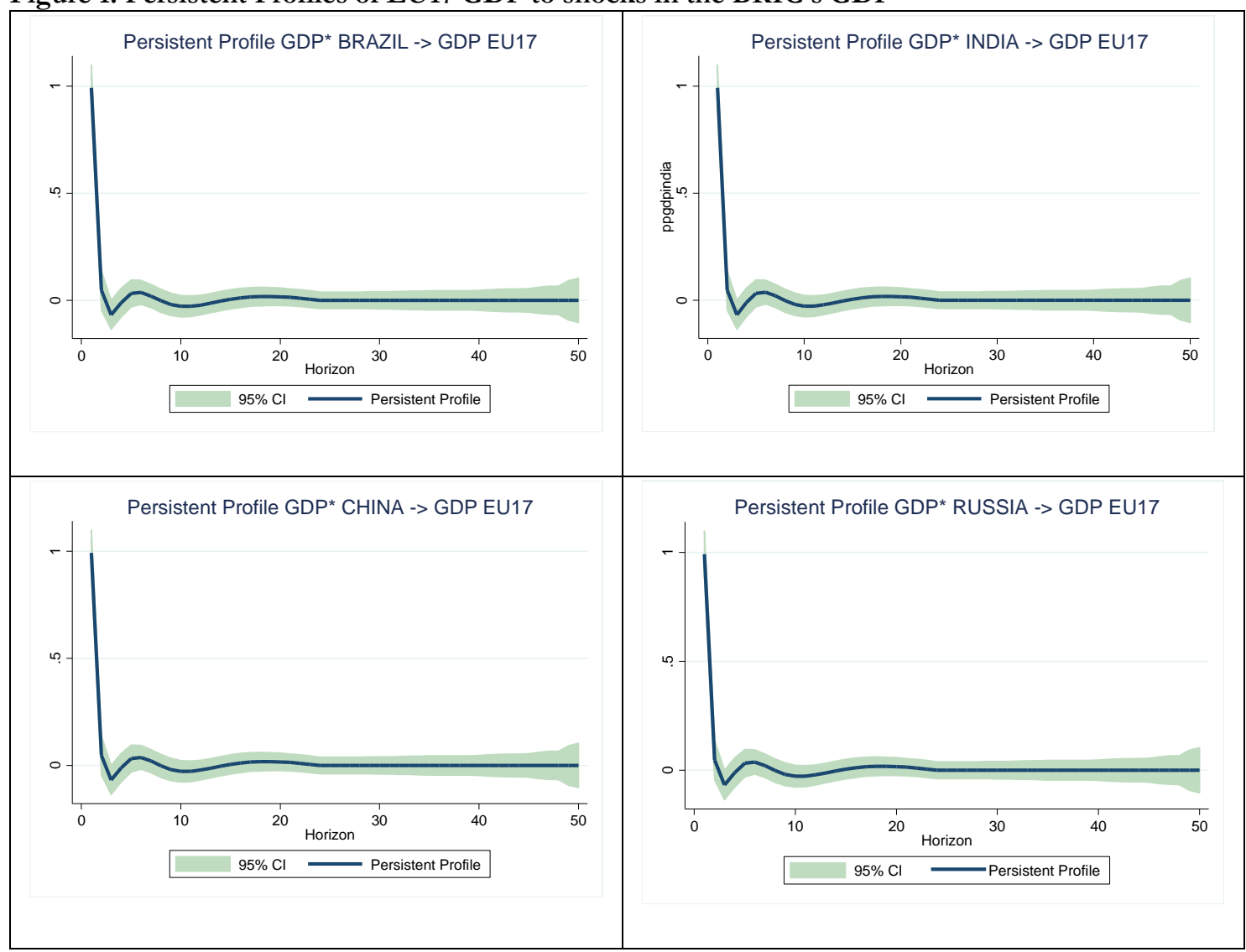

Next, Figure 2 presents the persistent profile of the US GDP to the various shocks in the GDP of the BRICs. According to these results, no persistent effect is evident since in less than approximately four (4) quarters all effects seem to die out. Hence, the US GDP is 
only affected in the short run by the shocks in the various GDPs.

Figure 2: Persistent Profiles of US GDP to shocks in the BRIC's GDP

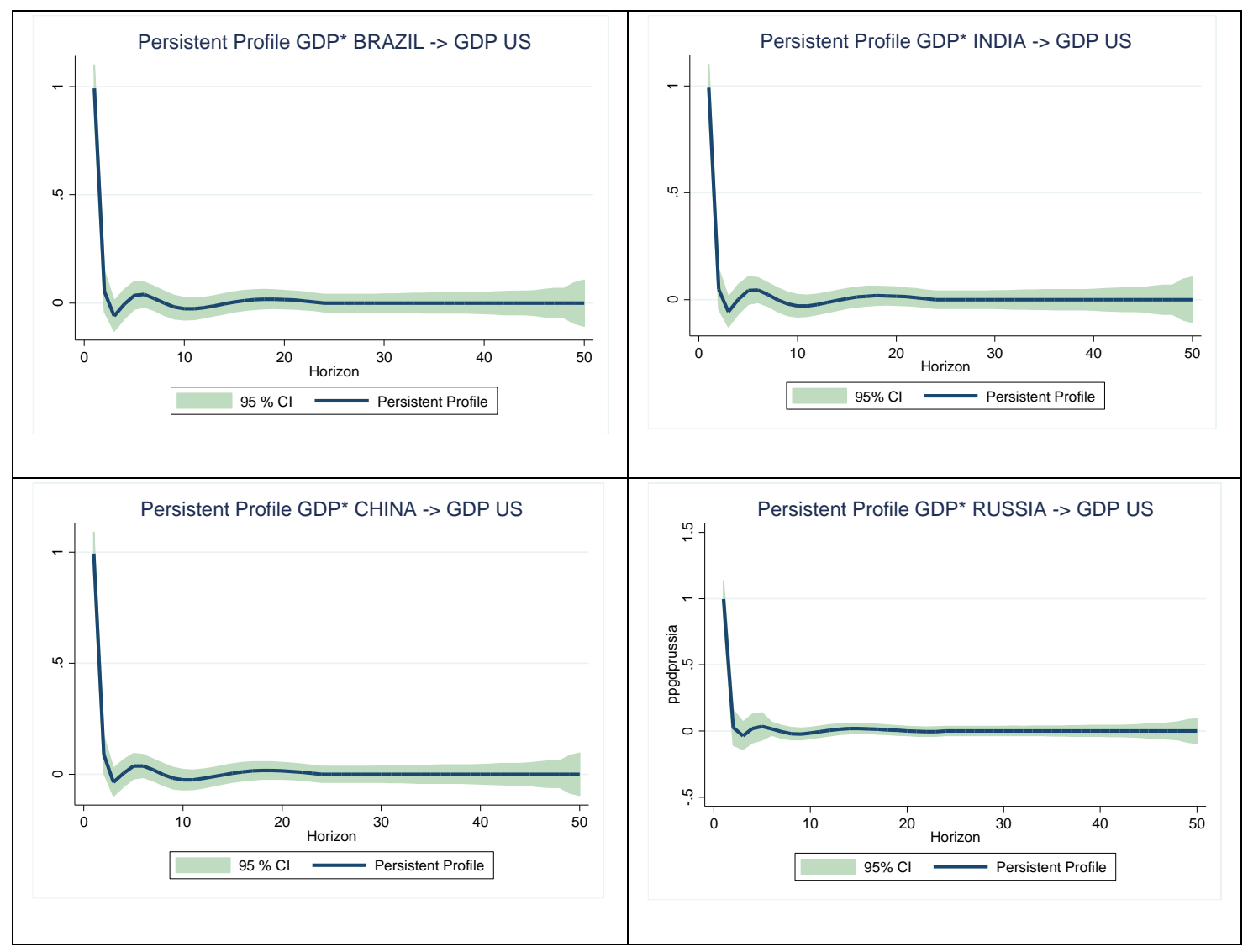

\subsection{Generalized Impulse Response Functions}

Next, having explored the persistent profiles of the various shocks in the BRICs on the GDP of the dominant economies (US, EU17), we will proceed with the presentation of the GIRFs. Each GIRF shows the dynamic response of the GDP of each economy to unit shocks in the rest of the economies' GDP, for up to 4 years.

We will base our analysis of Generalized Impulse Response Function (GIRFs) on the robust confidence bands (bootstrapped, 10.000 iterations) rather than the point estimates in order to avoid any possible structural instability. Since we are mainly interested in the 
impact of a sudden change in the economic activity of the BRICs (e.g. potential slowdown) and its impact on EU and US economic activity, we focus on the impact of a unit shock in the BRICs GDP on the GDP of the EU17 (Figure 5) and US (Figure 6). 

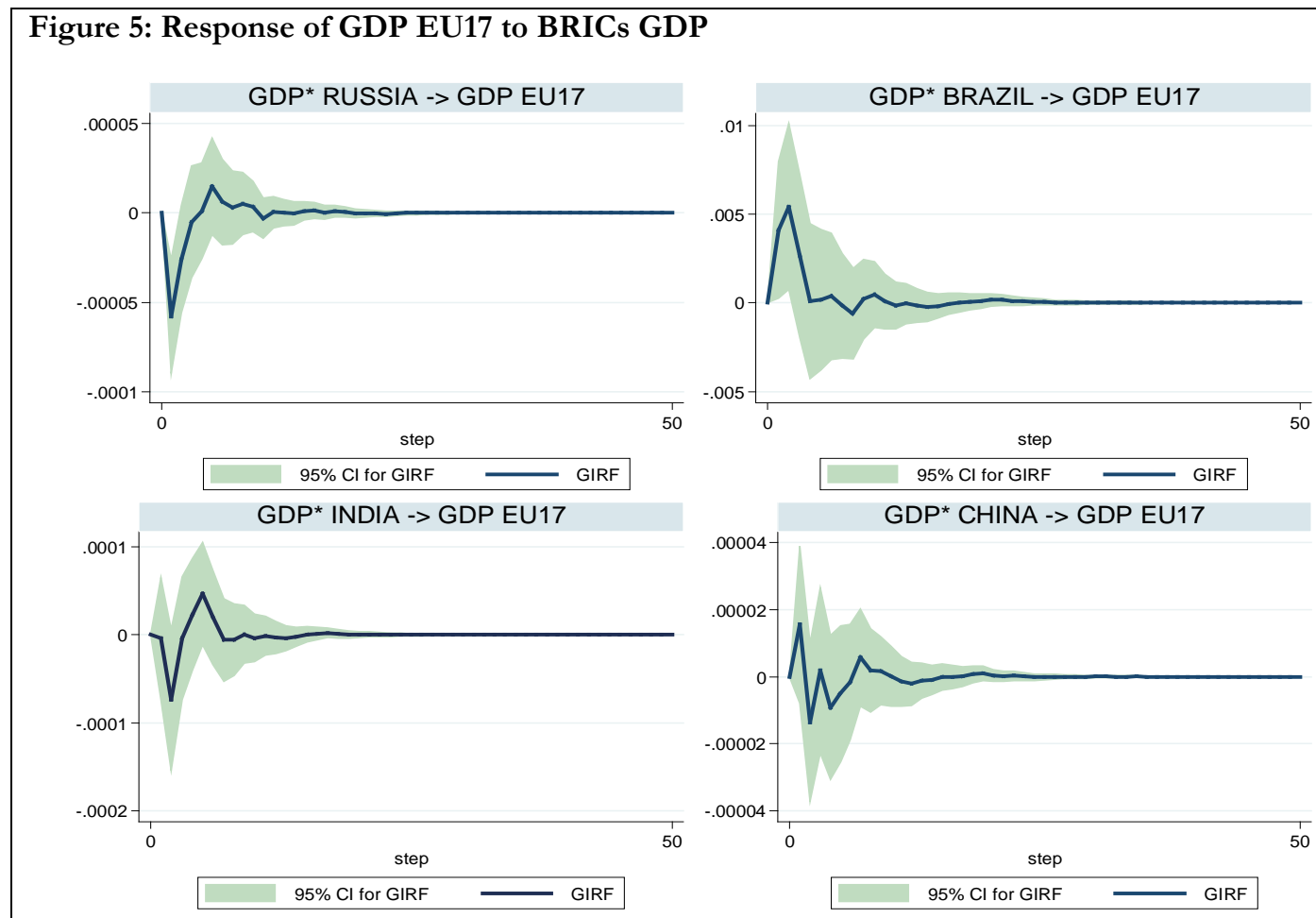

Figure 6: Response of GDP US to BRICs GDP
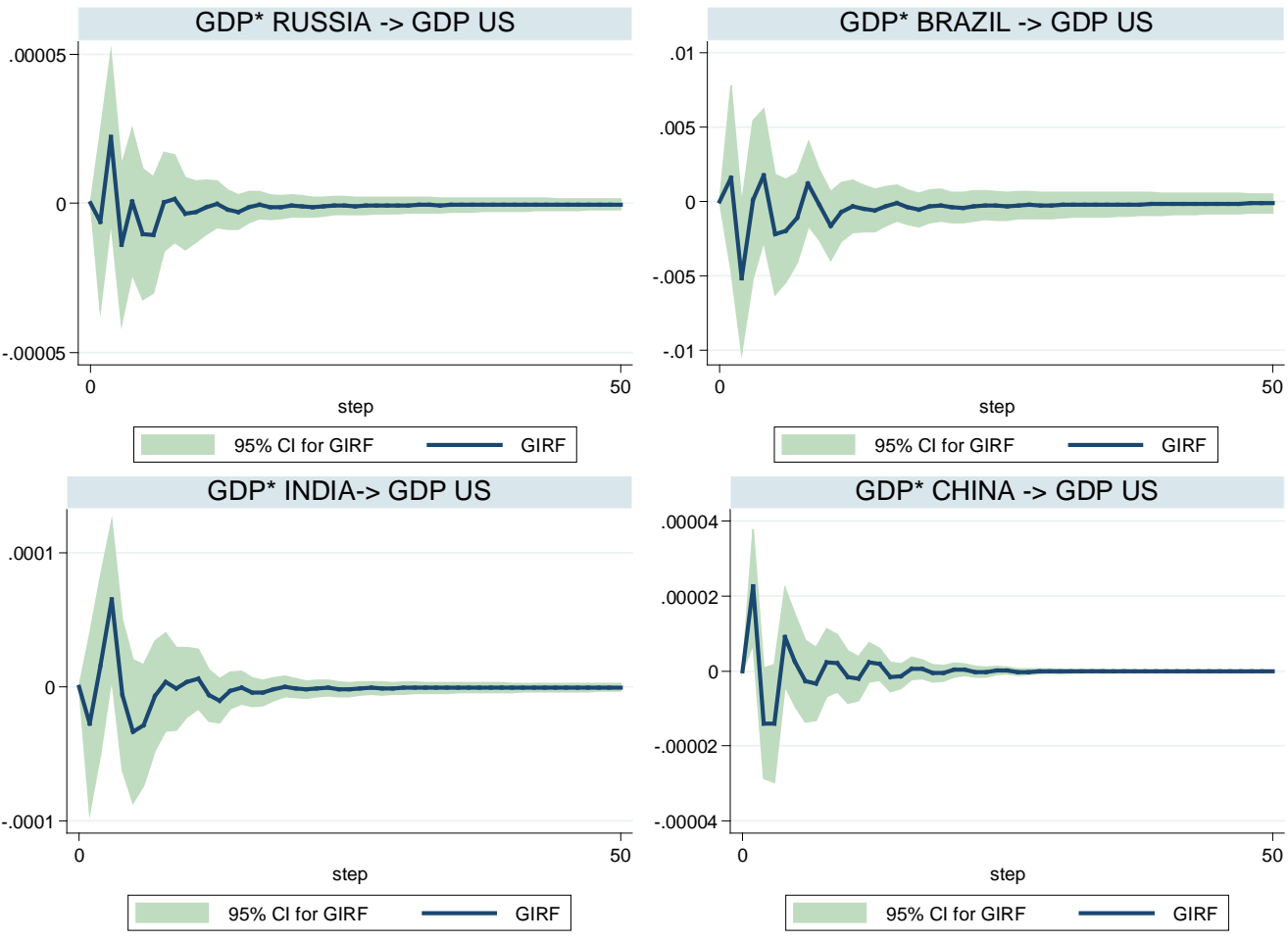
The robustness of the results is confirmed by the stability of the system (Figure 7).

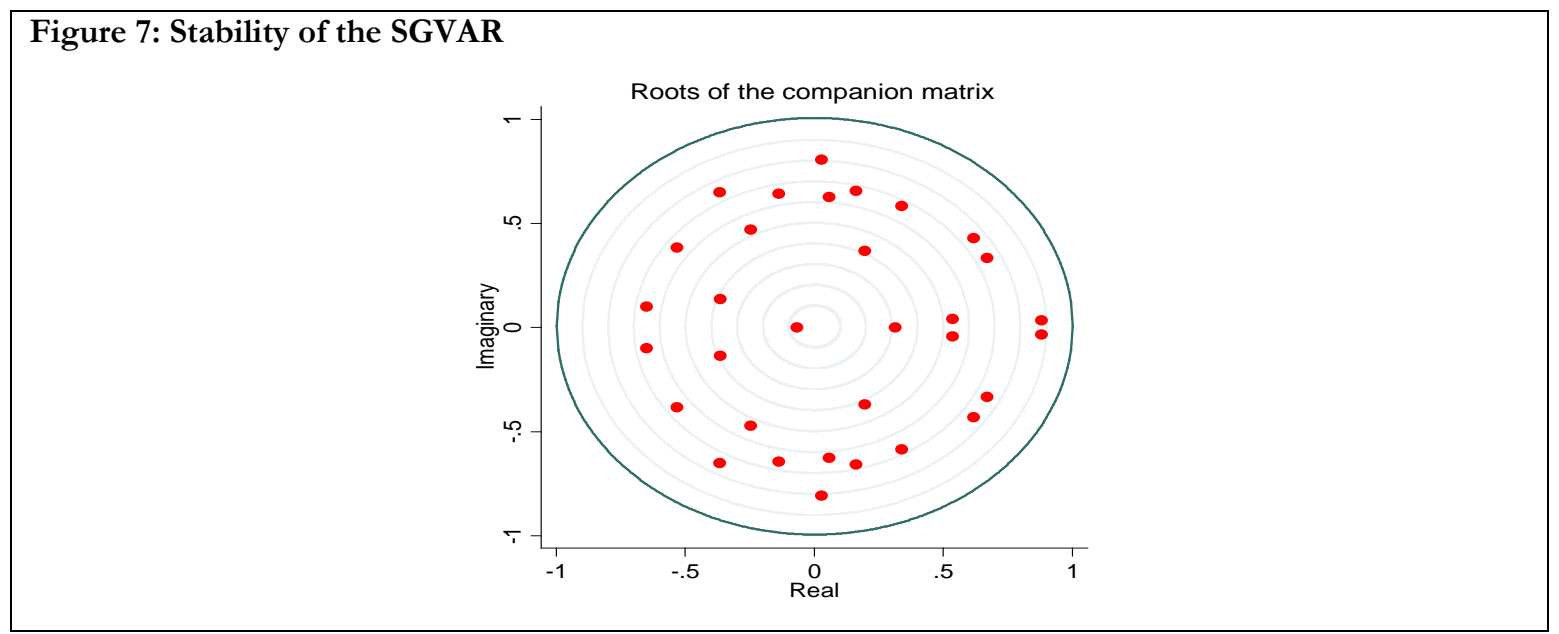

\subsection{Comparison of results: one (1) VS two (2) dominant economies}

In what follows, we will provide a thorough comparison between a system GVAR (SGVAR) featuring one (1) and (2) two dominant economies, respectively, visually and formally.

\subsubsection{Visual Comparison}

Due to the increasing significance of the Chinese economy in the global economy, we focus on the economy of China and how it is affected by a unit shock in either the interest rate or the GDP in the economies of US, $\mathrm{EU}^{8}$. In this context, Figure 8 presents the response of the Chinese GDP on a unit shock on either US or EU17 GDP, when both economies are treated as dominant in the GVAR system, while Figure 9 presents the response of the Chinese GDP to a unit shock on either US or EU17 GDP, when only the US economy is treated as dominant.

\footnotetext{
${ }^{8}$ We would like to thank an anonymous referee for this suggestion.
} 


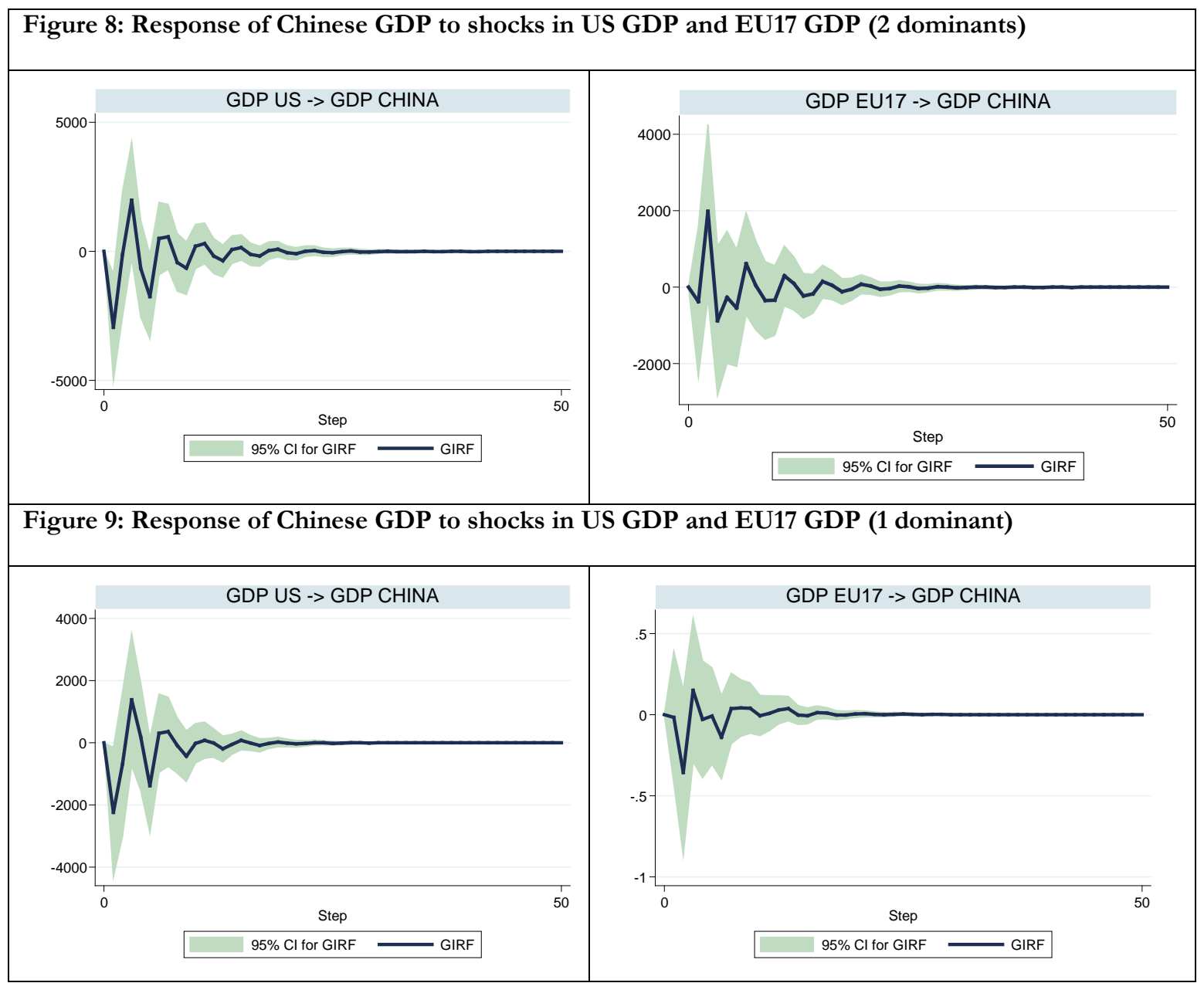

The results indicate that in the case of two (2) dominant economies, the US GDP seems to statistically significantly affect - in the short-run - the Chinese GDP, while if we rely on the one (1) dominant unit case, this does not seem to be true. Also, the Chinese GDP react differently to a shock in the EU17 GDP when the EU17 economy is dominant, than when the EU17 is not dominant.

Next, Figure 10 shows the response of the Chinese GDP in a unit shock in the Interest Rate of either US or EU17, when both economies are treated as dominant in the GVAR system. Figure 11 shows the response of the Chinese GDP in a unit shock in the Interest Rate of EU17 and US, when only the US economy is treated as dominant. 


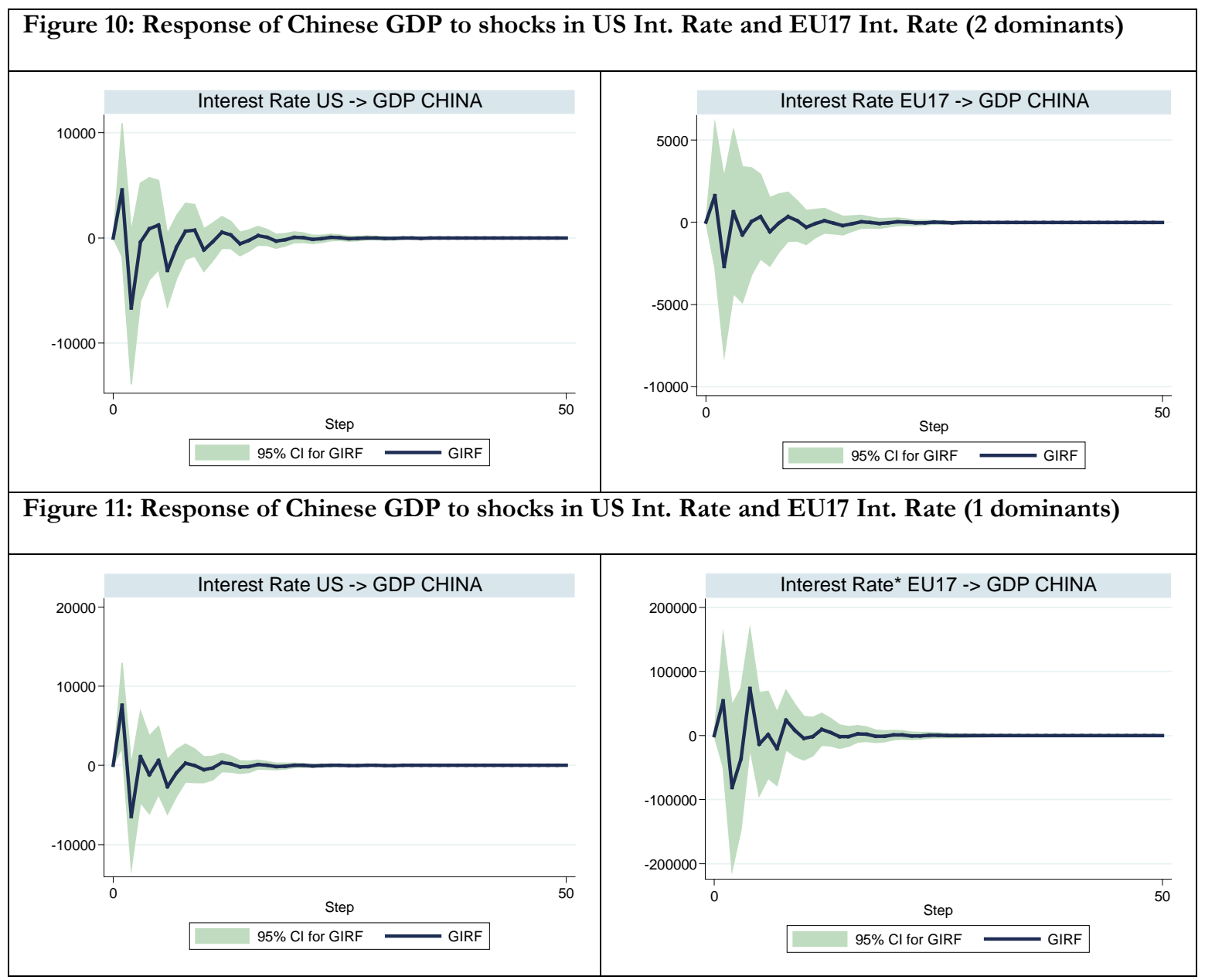

The results indicate that no significant differences are present in the GIRFs of the Chinese GDP regarding the unit shocks in the Interest Rates of US and EU17 in neither the case when both EU17 and US are treated as dominant, nor in the case when only the US economy is treated as dominant. Also, we can see that the in the two dominants case, the various GIRFs present a slightly faster of convergence to equilibrium.

As a result, the comparison of the GIRF's of the two GVAR models i.e. the classical GVAR model described above featuring one (1) dominant entity and the SGVAR system proposed in this paper with two (2) dominants shows, as expected, that most of the 
responses (GIRF figures) are quite similar in pattern but different in measures and timing. Hence, a thorough comparison of the two cases is relevant, based on formal methods.

\subsubsection{Formal Comparison}

In what follows, we will provide a comparison between a system GVAR featuring one (1) and (2) two dominant economies, respectively, using various formal criteria and methods.

\section{a) Brody's (1997) criterion}

According to Brody's (1997) methodology set out earlier, the normalized eigenvalues are presented below (Table 7). Since, there are (2) two normalized eigenvalues with $\rho\left(i^{*}\right)>0.4$, namely $\rho_{1}=1, \rho_{2}=0.72$, Brody's criterion is in favour of the existence of two (2) dominant economies in the model, instead of one (1).

Table 7: Normalized Eigenvalues of matrix $Q$

\begin{tabular}{|c|c|}
\hline Eige $\square$ value & $\rho_{\iota}$ \\
\hline 1 & 1.000 \\
\hline 2 & 0.720 \\
\hline 3 & 0.330 \\
\hline 4 & 0.180 \\
\hline 5 & 0.080 \\
\hline 6 & 0.040 \\
\hline 7 & 0.020 \\
\hline 8 & 0.002 \\
\hline 9 & 0.003 \\
\hline
\end{tabular}




\section{b) Information Criteria}

In order to provide a thorough comparison of the system GVAR featuring one (1) or (2) two dominant economies, respectively, we re-estimated the proposed GVAR system using, this time, only one dominant, i.e. the US economy. In this context, Table 8 presents the various information criteria for both cases.

Table 8: Information Criteria of the system GVAR with one and two dominant units, respectively.

\begin{tabular}{|c|c|c|c|c|}
\hline Dominant Economies & FPE & AIC & HQIC & BIC \\
\hline US and EU17 & -430.25 & -530.89 & -616.84 & -745.28 \\
\hline US & -65.09 & -438.67 & -507.74 & -610.17 \\
\hline
\end{tabular}

The results presented in Table 8 , show that the model incorporating two (2) dominant units is superior, according to the various information criteria, to the one that employs only one (1) dominant unit, since all information criteria present their optimal values when two (2) dominant economies are employed.

\section{c) Fitting Criteria}

Furthermore, Table 9 below shows the overall fitting statistics for the two GVAR systems.

Table 9: Overall fitting statistics of the GVAR system with one and two dominant units, respectively

\begin{tabular}{|c|c|c|c|}
\hline Dominant Economies & Log likelihood & R-squared adjusted & RMSE \\
\hline US and EU17 & -1403.58 & 0.67 & 6172.5 \\
\hline US & -1171.65 & 0.58 & 665.35 \\
\hline
\end{tabular}


Again, the overall statistics of the GVAR system with two (2) dominants clearly outperforms the GVAR with one (1) dominant entity.

\section{d) Speed of Convergence}

Finally, we compare the two models, with two (2) and one (1) dominant units, respectively, by means of each model's speed of convergence to equilibrium. As is well known, a system's speed of convergence is governed by the spectral radius $\rho(T)$ of the coefficient companion matrix. As a results, the largest eigenvalue (in modulus) should be as small as possible since this will lead to the smallest spectral radius and, hence, to faster convergence rate (e.g. Hughes Hallet and McAdam, 1999).

In this context, Table 9, presents the spectral radius of the two GVAR systems, featuring one (1) and two (2) dominant economies, respectively.

Table 10: Spectral radius of the GVAR system with one and two dominant units, respectively.

\begin{tabular}{|c|c|}
\hline Dominant Economies & Spectral Radius \\
\hline EU17 and US & 0.88 \\
\hline US & 0.92 \\
\hline
\end{tabular}

According to Table 10, the spectral radius of the system with two (2) dominant units was calculated to be equal to $\rho(2)=0.88$ while in the case of one (1) dominant unit it was calculated to be equal to $\rho(1)=0.91$. Therefore, from the results of the two models presented above, again the two (2) dominants scheme outperforms the one (1) dominant scheme.

After all, the goal of researchers in quantitative sciences and applied data analysis is to construct systems whose coefficient matrix has as small a spectral radius as possible in order to accelerate convergence. Hence, the two (2) dominants case is clearly found to be superior to the one (1) dominant case according to the various formal criteria employed. 


\section{ANALYSIS AND DISCUSSION}

We will begin our analysis by the persistent profiles of the country specific shocks. Each persistent profile shows the time profiles of the effects of the variables-specific shocks on the potential cointegrating relations in the SGVAR model. In general, all persistent profiles presented in Figures 1-4 as expected, as the time horizon grows the value of each persistent profile tends to zero. In fact, all persistent profiles die out in less than ten (10) quarters, i.e. 2.5 years when all the cointegrating relationships tend to zero. In this context, taking into consideration the overall picture of the persistent profiles we can infer that the EU17 GDP seems to be more vulnerable that the US GDP to shocks in either the GDPs or the Interest rates of the BRIC economies, since it needs more time to overcome the potential shocks.

Now, we base our analysis on the results obtained by the Generalized Impulse Response Functions (GIRFs) along with the 95\% confidence bands that were generated using 10,000 iterations. In this context, significant divergence in a GIRF is represented by a confidence interval that does not include zero. In general, most of the GIRFs suggest a 95\% confidence interval that includes zero, since we did not witness persistent deviations from that equilibrium point. This finding is, more or less, expected and should - by no means - be considered as being surprising and has to do with the rationale of the methodology and the nature of the disturbances (unanticipated sudden shocks). After all, it is largely consistent with the pioneering works of Dées et al. (2005, 2007a), Pesaran et al. (2006) and numerous empirical GVAR studies in the literature thereafter. See, for instance, Dees et al. (2009), Castren et al. (2010), Chudik and Fratzscher (2011), Chudik and Pesaran (2011), Chudik and Pesaran (2013), Dees et al. (2014). ${ }^{9}$

\footnotetext{
${ }^{9}$ We would like to thank an anonymous referee for giving us the opportunity to clarify this issue.
} 
More specifically, we have seen that a shock in the GDP of Russia and China does not create a statistically significant divergence to EU17 GDP from its equilibrium position. Nevertheless, a unit shock in the GDP of Brazil seems to have a statistically significant positive short-run impact on the EU17 GDP that lasts for almost two-three (2-3) quarters and dies out after four (4) quarters, when it returns back to its initial equilibrium position.

This statistically significant effect of the Brazilian GDP on the EU17 GDP could be attributed, to a large extent, to the overall trade relationship between the two regions, since the EU is Brazil's first trading partner, accounting for $21.2 \%$ of its total trade (2013) (Europa, 2013). On the other hand, a shock in the GDP of India seems to have a statistically significant negative short run impact on the GDP of EU17, which in turn dies out after a year i.e. four (4) quarters, when the European GDP returns back to its initial equilibrium position. This statistically significant impact of India's GDP on EU 17 GDP could be attributed both to the increasing trade relations between the two regions as well as to the Agreement on Scientific and Technological cooperation of 2002 that made India one of the largest exporters of Information and Technology services to the EU.

Hence, EU17 seems to be, at least partly, vulnerable to the shocks of BRICS, a fact that could be attributed to the rising FDI flows from the BRICs to EU17. Therefore, it is evident that a potential slowdown of the BRICs economies will affect the EU17 economy as well.

Next, a shock in the GDP of either Russia, India or Brazil does not seem to have any statistically significant effect on the GDP of US. In contrast, a shock in the Chinese GDP seems to have a statistically significant positive effect, on the short run i.e. two-three (2-3) quarters in the GDP of US. Nevertheless, this effect dies out in less than one year when the US GDP returns back to its initial equilibrium position. The statistically significant impact of Chinese GDP could be attributed to the fact that China's central bank withholds large 
reserves of US dollars. In general, by taking into consideration all the aforementioned facts, it could be argued that a slowdown in the BRICs economies will have little - if at all - impact on the US economy. The empirical results are consistent with the literature arguing that EU17 is more vulnerable to shocks than the US (e.g. Aizenman et al. 2011).

Finally, China is only statistically significantly affected, in the short run, i.e. three (3) quarters, by a shock in the US GDP, which in turn dies out after one year, when the Chinese GDP returns back to its initial equilibrium position.

Of course, this impact could be attributed to the fact that the Yuan was pegged to the dollar for more than a decade, making the Chinese economy more vulnerable to US shocks but, at the same time, immune to shocks from all other regions, a fact which is also consistent with our findings (World Economic Outlook, 2013).

\section{CONCLUSION}

The point of departure of our investigation for constructing this model has been the need for an upgraded compact (macro)econometrictool that could incorporate both the complex interdependencies that exist between the various economic entities and the fact that in the global economy more than one of these entities could have a predominant role. In this context, we have extended the GVAR model of Chudik and Pesaran (2013), featuring one dominant economy, in order to incorporate more than one dominant entity. Additionally, based on the trade weight matrix that lies in the core of the GVAR framework, we have provided both an analytical procedure and an ex-post econometric criterion for the selection 
of dominant entities. We illustrated the dynamics of the proposed SGVAR model by assessing, among other things, the impact of a shock in the economic activity of the BRICs on the US and EU17 economies, respectively.

In brief, the present paper contributed to the research conducted on GVAR in the following ways: (a) it proposed system estimation for the GVAR with $K$ dominants; (b) it formally estimated a GVAR with two (2) dominant economies; (c) it set out a formal method for indentifying the number of dominant entities in a GVAR framework; (d) it set out a novel method based on network theory for selecting the dominant entities; (e) it compared the estimation results of GVAR using one dominant and two dominant economies, respectively; (e) it estimated impact of a shock in the economic activity of the BRICs on the US and EU17 economies, respectively.

According to our findings, the dominant economies are those of the USA and EU17, with the results suggesting that EU17 is more vulnerable than the USA to GDP shocks from the BRICs, implying that a potential slowdown in the BRICs would primarily affect the EU17 economy.

Additionally, the comparison between the SGVAR featuring one (1) and two (2) dominant entities, respectively, showed that the two (2) dominant model's performance was superior based on the results of several formal criteria.

Of course, there are several ways in which the present study could be extended. From a macroeconomic point of view, it could be further investigated whether the US and international financial crisis played a distinct role in each country's financial system, whereas other crucial variables could be investigated. 
From a technical point of view, for example, a Bayesian GVAR could be adopted, whose main advantage is the possibility of mixing different pieces of information (sample information, prior information, etc) in order to construct a model that accounts for the stochastic character of the variables that could lead to a better approximation of reality.

In addition, the so-called World Input Output Table (WIOT) could serve as the tool to construct the GVAR weight matrix. With respect to the traditional GVAR approach, such a weight matrix - derived based on Leontief's Input Output matrix -, would be capable of accurately expressing the total, i.e. direct and indirect (e.g. intermediate flows) linkages between the various economies. Hence, the modeling of the world economy would be complete since there would be no missing relationships and/or interconnection channels due to the fact that all economies would be explicitly and accurately included in the GVAR model. Undoubtedly, future research on the topic seems of great interest. 


\section{REFERENCES}

Aizenman, J., Chinn M. D. and H. Ito. (2010), " The Emerging Global Financial Architecture: Tracing and Evaluating the New Patterns of the Trilemma's Configurations,"Journal of International Money and Finance, 29(4): 615-641.

Allegret J-P and Sallenave A. (2014), "The Impact of real exchange rates adjustments on global imbalances: A multilateral Approach", Economic Modelling, 37:149-163.

Artis M.J., Kontolemis Z.G. and Osborn D.R. (1997), "Business cycles for G7 and European countries", Journal of Business 70: 249-279.

Bates S, Angeon V. and Ainouche A, (2014), " The pentagon of vulnerability and resilience: A methodological proposal in development economics using graph theory", Economic Modelling, 42:445-453.

Bergman U.M., Bordo M.D. and Jonung L. (1998), "Historical evidence on business cycles: the international experience", In Beyond Shocks: What Causes Business Cycles?, Jeffrey C, Schuh S (eds). Federal Reserve Bank of Boston: Conference Series no. 42; 65-113.

Bernanke B, Boivin J, Eliasz P (2005), "Measuring monetary policy: a factor augmented vector autoregressive (FAVAR) approach", Quarterly Journal of Economics 120: 387422.

Bonacich, P. (1987), "Power and Centrality: A Family of Measures", American Journal of Sociology 92: 1070-82.

Bonacich, P., (1972)“Factoring and weighting approaches to status scores and clique identification", Journal of Mathematical Sociology 2, 113-120.

Bonacich, P., Lloyd, P., (2001),"Eigenvector-like measures of centrality for asymmetric relations", Social. Networks 23 (4), 191-201.

Brody A. (1997), "The second Eigenvalue of the Leontief Matrix", Economic Systems Research, 9(3):253-258.

Cakir M. Y. and Kabundi A. (2013), "Trade shocks from BRIC to South Africa: A Global VAR analysis", Economic Modelling, 32, 190-202.

Canova, F. and Marrinan, J. (1998), "Sources and propagation of international cycles: common shocks or transmission?", Journal of International Economics, 42:133-67.

Castren, O., S. Dees, and F. Zaher (2010), "Stress-testing euro area corporate default probabilities using a global macroeconomic model", Journal of Financial Stability, 6 (2): 64-78.

Cesa-Bianchi, A. (2013). "Housing cycles and macroeconomic fluctuations: A global perspective", Journal of International Money and Finance 37: 215-238.

Cetorelli N and Goldberg S. L., (2011), "Global Banks and International Shock transmission: Evidence from the Crisis", IMF Economic Review, 59: 41-76.

Chudik A. and Smith V., (2013), "The GVAR approach and the dominance of the U.S. economy,"Globalization and Monetary Policy Institute Working Paper 136, Federal Reserve Bank of Dallas.

Chudik, A. and M. H. Pesaran (2011), "Infinite dimensional VARs and factor models", Journal of Econometrics, 163: 4-22.

Chudik, A. and M.H. Pesaran (2013), "Econometric Analysis of High Dimensional VARs Featuring a Dominant Unit". Econometric Reviews, 32, 592-649. 
Chudik, A. and R. Straub (2011)."Size, openness, and macroeconomic interdependence", Globalization and Monetary Policy Institute Working Paper No. 103, Federal Reserve Bank of Dallas.

Chudik, A. and M. Fratzscher (2011), "Identifying the global transmission of the 2007-2009 Financial crisis in a GVAR model", European Economic Review 55 (3): 325-339.

CIA (2013), World Factbook.

Clark, T. E. and Shin, K. (2000), "The sources of fluctuations within and across countries, in Intranational Macroeconomics, Hess C, van Wincoop E (eds), Cambridge University Press: Cambridge, UK; 189-220.

Dees, S., M. H. Pesaran, L. V. Smith, and R. P. Smith (2014), "Constructing multicountry rational expectations models", Oxford Bulletin of Economics and Statistics, 76(6): 812840.

Dées S and N Zorell, (2012), "Business Cycle Synchronisation: Disentangling Trade and Financial Linkages," Open Economies Review, 23(4): 623-643.

Dées, S. di Mauro, F., Pesaran, H. and Smith, V. (2005), "Exploring the International Linkages of the Euro Area: A Global VAR Analysis", Working Paper Series, No 568, December.

Dées, S. M. HashemPesaran, L. Vanessa Smith and Ron P. Smith (2009), "Identification of New Keynesian Phillips Curves from a Global Perspective," Journal of Money, Credit and Banking, 41: 1481-1502.

Dées, S., F. di Mauro, M. H. Pesaran, L. V. Smith (2007a), "Exploring the International Linkages of the Euro Area: a Global VAR Analysis", Journal of Applied Econometrics, 22:1-38.

Dreger C. and Zhang Y. (2014), "Does Economic Integration of China affect growth and inflation in industrial countries?”, Economic Modelling, 38:184-189.

Eickmeier, S. (2007), "Business cycle transmission from the US to Germany - a structural factor approach", European Economic Review, 51: 521-51.

Eickmeier, S. and T. Ng (2015), "How do US credit supply shocks propagate internationally? A GVAR approach", European Economic Review, 74: 128-145.

Fagiolo, G., Reyes, J., Schiavo, S., (2008), “On the topological properties of the world tradeweb: a weighted network analysis”,PhysicaA387, 3868-3873.

Freeman, L.C., (1979), “Centrality in networks: I. Conceptual clarification”,Social Networks 1, 215-239.

Greenwood-Nimmo, M., V.H. Nguyen and Y. Shin (2011), Probabilistic Forecasting of Output, Growth, Inflation and the Balance of Trade in a GVAR Framework, Journal of Applied Econometrics, 27(4), pp. 554-573.

Hughes Hallett, A. and Mc Adam, P. (1999), Analyses in Macroeconomic Modelling, Springer. 
Johansen, S. and Juselius, K. (1990), "Maximum Likelihood Estimation and Inference on Cointegration with Applications to the Demand for Money," Oxford Bulletin of Economics and Statistics, 52(2):169-210.

Kapetanios G. and Pesaran M.H. (2007), “Alternative approaches to estimation and inference in large multifactor panels: small sample results with an application to modelling of asset returns". In The Refinement of Econometric Estimation and Test Procedures: Finite Sample and Asymptotic Analysis, Phillips G, Tzavalis E (eds). Cambridge University Press: Cambridge, UK.

Konstantakis N. K. and Michaelides G. P. (2014), "Transmission of the Debt Crisis: From EU15 to USA or vice versa? A GVAR Approach", Journal of Economics and Business, 76:115-132.

Koop, G. (2013), "Forecasting with Medium and Large Bayesian VARs", Journal of Applied Econometrics,28: 177-203.

Koop, G., M.H. Pesaran and S.M. Potter (1996), Impulse response analysis in nonlinear multivariate models, Journal of Econometrics 74, 119-47.

Korobilis, D. (2013a), "Assessing the Transmission of Monetary Policy Using Timevarying Parameter Dynamic Factor Models", Oxford Bulletin of Economics and Statistics 75(2): 157-179.

Korobilis, D. (2013b), "VAR forecasting using Bayesian Variable Selection", Journal of Applied Econometrics, 28: 204-230 .

Kose, M.A. (2002), "Explaining business cycles in small open economies: how much do world prices matter?”,Journal of International Economics 56: 299-327.

Kwark, N. S. (1999), "Sources of international business fluctuations: country-specific shocks or worldwide shocks?", Journal of International Economics, 48: 367-85.

Lagana G, Mountford A. (2005), Measuring monetary policy in the UK: a factoraugmented vector autoregression model approach. Manchester School 73(S1): 77-98.

Mariolis T, and Tsoulfids L. (2014), “On Brody's Conjecture: Theory, Facts and Figures about instability of the US economy", Economic Systems Research, 26(2):209-223.

Pesaran M. Hashem and L. Vanessa Smith \& Ron P. Smith, (2007), "What if the UK or Sweden had joined the euro in 1999? An empirical evaluation using a Global VAR," International Journal of Finance \& Economics, 12(1): 55-87.

Pesaran, M. H. and R. P. Smith (2006), "Macroeconomic Modelling with a Global Perspective", Manchester School, University of Manchester, 74: 24-49.

Pesaran, M. H. and Shin, Y. (1998), 'Generalized impulse response analysis in linear multivariate models, Economics Letters58 (1), 17-29.

Pesaran, M. H., T. Schuermann. and S. M. Weiner (2004), "Modelling Regional Interdependencies Using A Global Error-Correcting Macroeconometric Model", Journal of Business and Economics Statistics, 22: 129-162.

Pesaran, M. H., and Holly, S and Dees, S. and Smith, L. V, (2007), "Long Run Macroeconomic Relations in the Global Economy," Economics - The Open-Access, OpenAssessment E-Journal, Kiel Institute for the World Economy, vol. 1, pages 1-20.

Schwarz, G. E. (1978), "Estimating the dimension of a model", Annals of Statistics, 6 (2): 461-464. 
Stock James H. and Mark W. Watson, (2005) "Understanding Changes In International Business Cycle Dynamics," Journal of the European Economic Association, 3(5): 968-1006.

World Economic Output, October 2013.

$\mathrm{Xu}, \mathrm{T} . T$. (2012), The role of credit in international business cycles, Cambridge Working Papers in Economics No 1202, University of Cambridge.

Ying F. and Suting R. and Hongbo C. and Xuefeng C, (2014), "The state's role and position in international trade: A complex network perspective”, Economic Modelling, 39:71-81.

Zellner, A., and D. S. Huang.(1962), " Further properties of efficient estimators for seemingly unrelated regressionequations", International Economic Review 3: 300-313.

Zelner A. and Theil H. (1962), "Three-Stage Least Squares: Simultaneous estimation of Simultaneous Equations", Econometrica, 30(1):54-78. 


\section{APPENDIX}

A number of relevant tests need to be carried out.

\section{Stationarity}

We start by testing for stationarity. In case the time series employed are not stationary, we induce stationarity following, among others, Koop (2013).

There are several formal tests of stationarity, among which quite popular is the Phillips-Perron (PP) test. Phillips and Perron's test statistics can be viewed as a DickeyFuller statistics that have been made robust to serial correlation by using the Newey-West (1987) heteroskedasticity -and autocorrelation- consistent covariance matrix estimator. The main advantage of the PP tests over the ADF tests is that the PP tests are robust to general forms of heteroskedasticity in the error term $u_{t}$. Another important advantage is that no $a$ priori specification of the lag length for the test regression is required.

The Phillips-Perron(1988) test involves fitting the model:

$$
Y_{t}=a+\rho Y_{t-1}+\varepsilon_{t}
$$

where we may exclude the constant or include a trend term. There are two statistics, $Z_{\rho}$ and $Z_{\tau}$, calculated as follows:

$$
\begin{gathered}
Z_{\rho}=T\left(\widehat{\rho_{T}}-1\right)-\frac{1}{2} \frac{n^{2} \widehat{\sigma^{2}}}{s_{T}^{2}}\left(\widehat{\lambda_{T}^{2}}-\widehat{\gamma_{0, T}}\right) \\
Z_{\tau}=\sqrt{\frac{\widehat{\gamma_{0, T}}}{\widehat{\lambda_{T}^{2}}} \frac{\widehat{\rho_{T}}-1}{\hat{\sigma}}-\frac{1}{2}\left(\widehat{\lambda_{T}^{2}}-\widehat{\gamma_{0, T}}\right) \frac{1}{\widehat{\lambda_{T}^{2}}} \frac{T \hat{\sigma}}{s_{T}}}
\end{gathered}
$$

where $\gamma_{j, T}=\frac{1}{T} \sum_{t=j+1}^{T} \widehat{u_{t}} \widehat{u_{t-J}}, \widehat{\lambda_{T}^{2}}=\widehat{\gamma_{0, T}}+2 \sum_{j=1}^{q}\left(1-\frac{j}{q+1}\right) \gamma_{j, T}$ and $s_{T}^{2}=\frac{1}{T-k} \sum_{t=1}^{T} \widehat{u_{t}^{2}}$

where $u_{t}$ is the OLS residual, $\mathrm{k}$ is the number of covariates in the regression, $\mathrm{q}$ is the number of Newey-West lags to use in calculating $\lambda_{T}^{2}$, and $\hat{\sigma}$ is the OLS s.e. error of $\hat{\rho}$. 
Under the null hypothesis that $\rho=0$, the PP statistics, $Z_{\rho}$ and $Z_{\tau}$, have the same asymptotic distributions as the Augmented Dickey-Fuller (ADF) t-statistic and normalized bias statistics. If the series are not stationary, we induce stationarity by means of first differencing.

\section{Optimum Lag Length}

We make use of the BIC (Schwartz 1978) and the optimum lag length is given by the following objective function:

$$
\hat{\xi}=\operatorname{argmin}_{\xi \leq n}\left\{-2 \frac{\ln (L L(\xi))}{n}+\xi \frac{\ln (n)}{n}\right\}
$$

where $\operatorname{LL}(\xi)$ is the $\log$-likelihood function of a $\operatorname{VAR}(\xi)$ model, $\mathrm{n}$ is the number of observations and $\xi$ is the number of lags and $\hat{\xi}$ is the optimum lag length selected.

\section{Cointegration}

We have to check for cointegration, since if cointegration is present then the Error Correction Terms have to be employed in the estimation of the GVAR model. We employ the popular Johansen (1988) methodology that allows for more than one cointegrating relationship, in contrast to other tests. The methodology is based on the following equation:

$$
\begin{gathered}
\Delta y_{t}=m+\Pi y_{t-1}+\sum_{i=1}^{p-1} \Gamma_{l} \Delta y_{t-i}+e_{p} \\
\text { where: } \Pi=\sum_{i=1}^{p} A_{i}-I \text { and } \Gamma_{i}=-\sum_{j=i+1}^{p} A_{p}
\end{gathered}
$$

The existence of cointegration depends upon the rank of the coefficient matrix $\Pi$ which is tested through the likelihood ratio, namely the trace test described by the following formulas:

$$
J_{\text {trace }}=-T \sum_{i=r+1}^{k} \log \left(1-\lambda_{i}\right)
$$

where: $\mathrm{T}$ is the sample size and $\lambda_{i}$ is the largest canonical correlation. 
The trace test tests the null hypothesis of $r<n$ cointegrating vectors and the critical values are found in Johansen and Juselius (1990). Also, having stationary variables in the system is not an issue according to Johansen (1995) as long as all the time series are integrated of the same order.

\section{Asymptotic Properties}

For the purpose of estimation and inference in stationary models, Chudik and Pesaran (2011a) showed that the relevant asymptotics are:

$$
\frac{T}{N} \rightarrow k<\infty
$$

\section{Stability Conditions}

Following Pesaran et al. (2002) and Mutl (2009), it is not sufficient to examine the countryby-country stability. In this work, to determine whether the model is stable, we check the stability of the whole system. Hence, we require that: $\rho_{\text {system (i) }}<1$ for stability, where $\rho_{\text {system (i) }}$ is the spectral radius of the system's matrix. 